\title{
Correlation Between Ultrasonic Testicular Volume and Seminal Fluid Analysis in Men with Infertility
}

\author{
Sadiq Abu, Hadijat O. Kolade-Yunusa, Terkaa Atim, F. Ehimatie Obakeye, and Nuhu K. Dakum
}

\section{ABSTRACT}

Background: Infertility is a major cause of marital disharmony in Nigeria because of the high premium placed on childbearing. Unfortunately, the blame is on the woman most times in Nigeria. Seminiferous tubules comprise $\mathbf{8 0 - 9 0 \%}$ of testicular mass. Thus, the testicular volume is an index of spermatogenesis. Therefore, accurate testicular volume will help in assessing testicular function if there is no obstruction. This study was conducted to evaluate the correlation between testicular volume, measured by ultrasound and conventional sperm parameters (semen volume, sperm concentration, sperm motility and sperm morphology) in men with infertility presenting to Urology Division, University of Abuja Teaching Hospital, Gwagwalada Abuja.

Methodology: This was a descriptive cross sectional study, male subjects with infertility presenting to University of Abuja Teaching Hospital were recruited into the study. The testicular volume of all the subjects was measured by ultrasonography. The semen samples were collected by the process of masturbation on day five of sexual abstinence and analyzed according to WHO criteria 2010. Collated data were analyzed using SPSS version 20.0. $P$-value $<0.05$ was taken as statistically significant.

Results: The average total testicular volume (TTV) of men with infertility was $19.83 \mathrm{ml}$ while mean testicular volume (MTV) was $10.24 \mathrm{ml}$. There was a statistically significant difference between MTV and semen volume $(\mathrm{r}=0.391, \mathrm{p}=\mathbf{0 . 0 0 0})$, and sperm concentration $(\mathrm{r}=\mathbf{0 . 6 3 9}, \mathrm{p}=\mathbf{0 . 0 0 0})$. There was a weak and insignificant correlation between MTV and sperm motility and MTV and morphology $(r=0.216, p=0.055$ and $r=0.076, p=0.502)$ respectively. Linear regression analysis showed significant impact of MTV $(\mathrm{P}<0.001)$ on sperm concentration with a critical MTV of $\leq 10 \mathrm{ml} .0$ indicating poor testicular function (severe oligospermia)

Conclusion: The mean ultrasonic testicular volume in men with infertility in this study was $10.24 \mathrm{ml}$ and there was a significant positive correlation of MTV with semen volume and sperm concentration. Although, there was correlation of MTV with sperm motility and morphology, this was not significant. The critical mean ultrasonic testicular volume indicating poor testicular function (severe oligospermia) was found to be $10 \mathrm{ml}$. This study has shown that the mean ultrasonic testicular volume can be a pointer to semen volume and sperm concentration in evaluating men with infertility.

Keywords: Infertility, testicular volume, ultrasound scan, testicular function, seminal fluid analysis, WHO 2010.

\section{INTRODUCTION}

Infertility is the failure to achieve conception despite one year of regular unprotected sexual intercourse [1]. Male infertility refers to the inability of a male to achieve a pregnancy in a fertile female [1]. Infertility is a condition that causes intense mental agony and trauma that can best be described by the infertile couples themselves. The incidence of infertility is between $10-15 \%$ and approximately 13 to 19 million couples are likely to be infertile in a country at any given time according to WHO [2]-[4]. The prevalence of infertility has been quoted to be highly variable in SubSahara Africa, ranging from $20-46 \%$ [5]. Given that a male
Published Online: January 30, 2021

ISSN: 2593-8339

DOI: $10.24018 /$ ejmed.2021.3.1.541

\section{S. Abu*}

Urology unit, Zenith Medical and Kidney Center, Abuja, Nigeria.

Department of Surgery, University of Abuja Teaching Hospital, Abuja, Nigeria. (e-mail:abusadiqnewton2000@ gmail.com) H. O. Kolade-Yunusa

Department of Radiology, University of Abuja Teaching Hospital, Abuja, Nigeria. College of Health Sciences, University of Abuja, Abuja, Nigeria.

T. Atim

Department of Surgery, University of Abuja Teaching Hospital, Abuja, Nigeria. College of Health Sciences, University of Abuja, Abuja, Nigeria.

F. E.Obakeye

Department of Obstetrics and Gynaecology, University of Abuja Teaching Hospital, Abuja, Nigeria.

\section{N. K. Dakum}

Department of Surgery, University of Jos Teaching Hospital/University of Jos, Plateau, Nigeria.

*Corresponding Author

factor can be the cause of infertility in $30-40 \%$ of couples and is contributing factor in $50 \%$ of cases, it is worthwhile to evaluate both partners concurrently.

The causes of male infertility are multi-factorial and can be explained by deficiencies in sperm formation, concentration, and transportation. The evaluation of the male patient should be rapid, non- invasive and cost effective. This usually entails good medical history, physical examination including palpation of the genital organs and seminal fluid analysis. Approximately $80-90 \%$ of the testicular volume is made up of seminiferous tubules and germ cells [6]. Testicular volume is an index of spermatogenesis and semen profiles in men [7]-[9]. 
Therefore, a reduction in the number of germ cells is manifested in a reduction in testicular volume [9].

The current testicular volume measurement methods include the use of calipers, an orchidometer or ultrasound scan [8]-[13]. While orchidometer is an 'age-long' conventional method, ultrasound scan is generally recognized as the most accurate method of measuring actual testicular volume [13], [14]. Current evidence shows that testicular volumes calculated using ultrasound scan measurement formula, namely Length $\times$ Width $\times$ Height $\times 0.71$ provide the closest estimate of the actual volume [13], [15], [16]. Previous studies have established the relationship between testicular volume and function [9]-[11], [14]. However, there is insufficient evidence to establish the critical mean testicular volume indicating poor testicular function evidenced by sperm concentration $\leq 5$ million sperms/ejaculate. This study will therefore help in the evaluation of males with infertility.

\section{Methodology}

This was a descriptive cross-sectional study of 80 subjects. Male patients seen in the Urology Clinic of the University of Abuja Teaching Hospital Gwagwalada with infertility and consented to the study were recruited. Male infertility in this study was defined as men who were unable to impregnate their wives after one year of regular unprotected sexual intercourse with abnormal SFA (semen concentration $<15 \mathrm{miliom} / \mathrm{ml}$ ). Subjects with factors that could affect testicular volume or seminal parameters, which include scrotal swellings except varicocoele, azoospermia, epididymorchitis, cryptorchidism, Previous testicular torsion, patients on hormone therapy-testosterone, insulin and thyroid therapy in the last six months, patients on drugs - fertility drugs, psychoactive drugs like cocaine, marijuana in the last six months were excluded. Ethical clearance was obtained from the health research ethics committee of the University of Abuja Teaching Hospital with a number: FCT/UATH/HREC/PR/535. Socio-demographic characteristics of the patients were obtained, and a thorough history taken. A detailed physical examination was carried out including genital examination. The presence of varicocoele was determined by inspection and palpation in standing position before and during the Valsalva maneuver and this was confirmed by ultrasound scan. Semen was collected according to WHO 2010 guidelines. The total testicular volume of each participant was measured by ultrasonography by a consultant radiologist and the mean testicular volume calculated. Semen was collected on day five after sexual abstinence for optimum sperm parameters in a clean, dry, biologically inert plastic container by the process of masturbation. Semen samples were collected in a room close to the laboratory and at home for patients who could not produce semen in the hospital with clear written and oral instructions on collection and transportation with emphasis on complete sample, that is, all the ejaculates were collected including the first sperm rich portion and the man reported any loss of any of the sample. The collected samples were allowed to liquefy at $37{ }^{\circ} \mathrm{C}$ for 30 minutes and analyzed within one hour after collection. Microscopic examination was carried out to record the sperm concentration, motility, and morphology of the sperm according to WHO Guideline (2010) in the microbiology research laboratory in University of Abuja Teaching Hospital by a consultant pathologist. Two semen samples were collected on two different occasions two weeks apart from each subject for analysis due to individual variability in semen parameters and the sample with better semen parameters was used for this study.

Regarding testicular volume determination, each subject was placed in a supine position with the legs slightly spread apart. Trousers and underwear were placed at the mid-thigh level. The scrotum was immobilized on a rolled towel placed between the patient's thighs. The penis was covered with a towel and the towel was taped to the abdominal wall.

The scrotum and its contents were scanned in two planes, after coupling gel was applied along the longitudinal and transverse axis to obtain grey scale images of each testis using light pressure to avoid distortion of the testicular shape. Testicular volume was calculated using: $\mathrm{L} \times \mathrm{W} \times \mathrm{H} \times$ 0.71 (L-length, longitudinal diameter, W-width, transverse diameter, H-height, AP diameter) and the total testicular volume (sum of right and left testes) determined. The mean total testicular volume was calculated by dividing the total testicular volume (TTV) by two. The presence of varicocoele was noted. All the subjects were scanned using EMF G70 ultrasound machine manufactured by Shenzhen Emperor Electronic Technology, China 2011 with 7.5MHZ curvilinear probe. Collated data were analyzed using SPSS version 20.0 and p-values less than 0.05 is considered to be statistically significant. Test of significance was done using independent T-tests for comparison between right and left testicular volume. Pearson correlation coefficient was worked out to assess the linear relationship of testicular volume with different sperm parameters. The impact of mean testicular volume on sperm concentration was done using linear regression analysis.

\section{RESULTS}

A total of 80 men with infertility were included in the study. The age range was 28-54years with a mean age of $39.1 \pm 6.1$ years. Most $(56.3 \%)$ of the subjects were in the 30 39years age group. There is no significant correlation between MTV of subjects with infertility and age $(r=-0.62$, $\mathrm{p}=0.586)$. More than half of the subjects were civil servants $(58 \%)$. More than half of the subjects $(62.5 \%)$ attained tertiary level of education (Table 1).

TABLE 1: SOCIO-DEMOGRAPHIC CHARACTERISTICS OF THE PATIENTS AND

\begin{tabular}{cccc}
\multicolumn{4}{c}{ TYPE OF INFERTILITY $(\mathrm{N}=80)$} \\
\hline \multirow{4}{*}{ Variable } & Frequency & Percentage \\
\hline & Civil servant & 47 & 58.7 \\
& Trader & 16 & 20.0 \\
& Artisan & 7 & 8.8 \\
\multirow{5}{*}{ Ethnicity } & Unemployed & 2 & 2.5 \\
& Others & 8 & 10.0 \\
& Others & 32 & 40.0 \\
& Igbo & 21 & 26.2 \\
& Hausa & 15 & 18.8 \\
& Yoruba & 12 & 15.0 \\
& Primary & 52 & 65.0 \\
& infertility & & \\
& Secondary & 28 & 35.0 \\
\hline
\end{tabular}




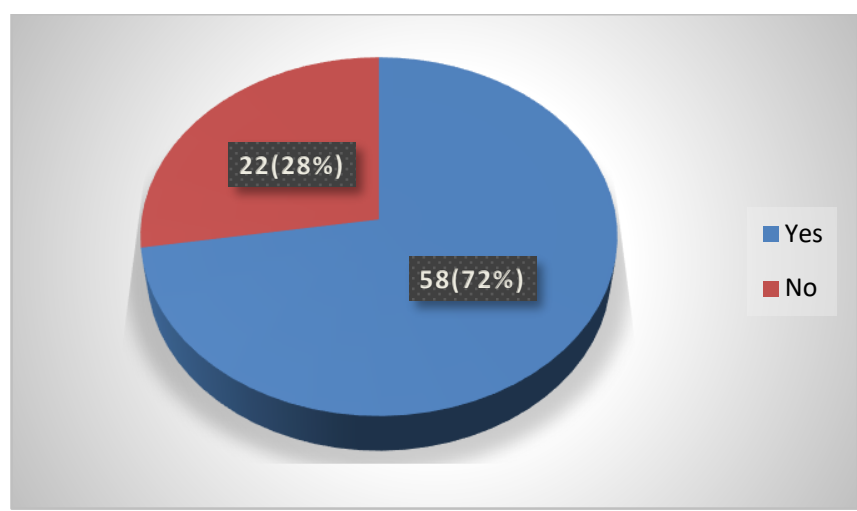

Fig. 1. Distribution of varicocoele among subjects with infertility.

There was no statistically significant difference between the mean testicular volume of infertile men with varicocoele and those without varicocoele $(\mathrm{p}=0.905)$.

TABLE 2: Right TESTICULAR VOLUME (RTV), LEFT TESTICULAR VOLUME (LTV), TOTAL TESTICULAR VOLUME (TTV) AND MEAN TESTICULAR VOLUME (MTV) OF SUBJECTS WITH INFERTILITY (N=80)

\begin{tabular}{ccccc}
\hline & RTV & LTV & TTV & MTV \\
\hline Mean volume $(\mathrm{ml})$ & 10.36 & 9.46 & 19.83 & 10.24 \\
Std. Deviation & 3.72 & 3.72 & 7.04 & 3.84 \\
\hline
\end{tabular}

TABLE 3: COMPARISON OF RIGHT TESTICULAR VOLUME (RTV) AND LEFT TESTICULAR VOLUME (LTV) OF SUBJECTS WITH INFERTILITY (N=80)

\begin{tabular}{lcccc}
\hline & $\begin{array}{c}\text { Mean } \\
\text { volume }(\mathrm{ml})\end{array}$ & $\begin{array}{c}\text { Std. } \\
\text { Deviation }\end{array}$ & $\mathrm{T}$ & p-value \\
\hline RTV & 10.36 & 3.72 & \multirow{2}{*}{1.531} & \\
LTV & 9.46 & 3.72 & & 0.128 \\
\hline
\end{tabular}

There was no significant statistical difference between right and left testicular volumes $(\mathrm{p}=0.128)$.

\begin{tabular}{|c|c|c|c|c|}
\hline & $\begin{array}{c}\text { Semen } \\
\text { Volume } \\
(\mathrm{ml})\end{array}$ & $\begin{array}{c}\text { Semen } \\
\text { Concentration } \\
\left(\mathrm{X} 10^{6} / \mathrm{ml}\right) \\
\end{array}$ & $\begin{array}{c}\text { Sperm } \\
\text { Motility } \\
(\%)\end{array}$ & $\begin{array}{c}\text { Sperm } \\
\text { Morphology } \\
(\%)\end{array}$ \\
\hline Mean & 2.59 & 6.52 & 25.62 & 62.34 \\
\hline Median & 2.15 & 5.35 & 17.50 & 70.00 \\
\hline Mode & 2.00 & 1.20 & 0.00 & 70.00 \\
\hline $\begin{array}{c}\text { Std } \\
\text { Deviation }\end{array}$ & 1.44 & 4.79 & 26.50 & 20.78 \\
\hline Minimum & 0.30 & 1.00 & 0.00 & 0.00 \\
\hline Maximum & 9.00 & 14.9 & 80.00 & 90.00 \\
\hline
\end{tabular}

\begin{tabular}{|c|c|c|c|}
\hline & $\begin{array}{l}\text { Pearson's } r \text { - } \\
\text { value }\end{array}$ & $p$-value & Interpretation \\
\hline MTV vs Age & 0.62 & 0.586 & $\begin{array}{l}\text { No Significant } \\
\text { Correlation }\end{array}$ \\
\hline $\begin{array}{l}\text { MTV vs Ethnic } \\
\text { Group }\end{array}$ & 0.096 & 0.396 & $\begin{array}{l}\text { No Significant } \\
\text { Correlation }\end{array}$ \\
\hline $\begin{array}{c}\text { MTV vs } \\
\text { Varicocoele }\end{array}$ & 0.27 & 0.905 & $\begin{array}{c}\text { No Significant } \\
\text { Correlation }\end{array}$ \\
\hline $\begin{array}{l}\text { MTV vs Semen } \\
\text { Volume }\end{array}$ & 0.391 & $<0.001$ & $\begin{array}{l}\text { Moderate Positive } \\
\text { Correlation }\end{array}$ \\
\hline $\begin{array}{c}\text { MTV vs } \\
\text { Concentration }\end{array}$ & 0.639 & $<0.001$ & $\begin{array}{l}\text { Strong Positive } \\
\text { Correlation }\end{array}$ \\
\hline MTV vs Motility & 0.216 & 0.055 & $\begin{array}{l}\text { Weak Positive } \\
\text { Correlation }\end{array}$ \\
\hline $\begin{array}{l}\text { MTV vs \%Normal } \\
\text { sperms }\end{array}$ & 0.07 & 0.502 & $\begin{array}{c}\text { Weak Positive } \\
\text { Correlation }\end{array}$ \\
\hline
\end{tabular}

Regression analysis on effect of MTV on sperm concentration shows a strong impact of MTV on sperm concentration $(\mathrm{p}<0.001)$.

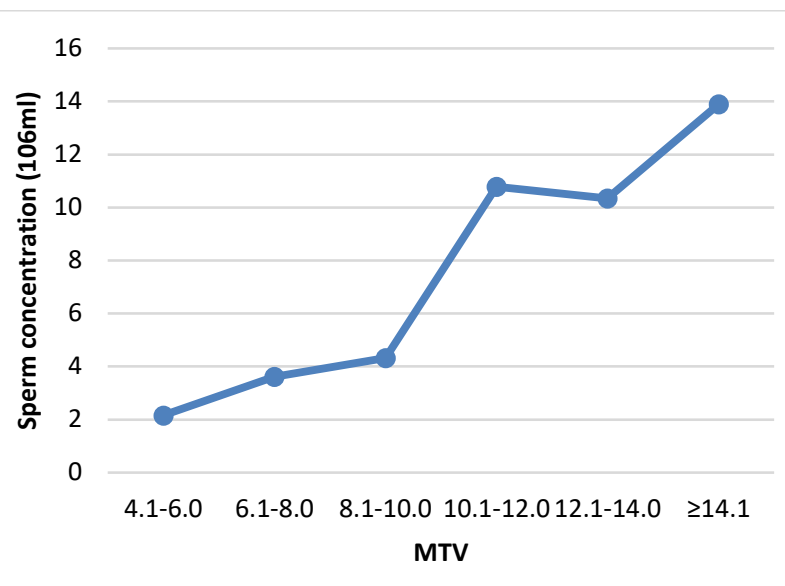

Fig. 2. A line graph of average sperm concentration and mean testicular volume (MTV) of subjects with infertility. Severe oligospermia $(<5 \mathrm{million} / \mathrm{ml})$ is associated with a critical mean testicular volume of $\leq 10 \mathrm{ml}$.

\section{DISCUSSION}

The analysis of semen is a cornerstone in the evaluation of male infertility. Seminiferous tubules comprise $80-90 \%$ of testicular mass and testicular volume is an index of spermatogenesis [1]. Though, positive correlation of ultrasonic testicular volume and testicular function has been established [9]-[12], [14], there is inconclusive evidence to establish the critical mean testicular volume indicating poor testicular function as evidenced by conventional semen parameters.

In this study, the mean age of the subjects was 39.1 years. This is similar to the mean age of 39 years found by Nwajiaku and colleagues in a study in Southeast Nigeria [4] and a recent study by Manuel et al. in PortHarcort who reported a mean age of 38.16 years [17]. However, it is higher than the mean age of 31.48 years found by Kristo and Dani in a similar study among Albanian subfertile males [18], 34.9 years among infertile Indian males by Sharath Kumar et al. [19] and 36.8years by KH Tijani in Lagos Nigeria [20]. However, the mean age in the different studies all fall into the reproductive age group. Most of the subjects were in the 30-39 year age group. This is not out of place since the subjects in the reproductive age group are the ones that present to fertility clinic.

There was no significant correlation between mean testicular volume and age of the subjects using Spearman correlation ( $\mathrm{r}=0.096, p=0.586$ ). This is consistent with the findings in a similar study by Kristo and Dani among subfertile men in Albania [18]. In contrast, Tijani et al. in a similar study in Lagos, Nigeria found a decline in the mean testicular volume with increasing age, however, it was not statistically significant [20].

The various ethnic groups in Nigeria were represented in this study which removes the possible ethnic influence on the measured testicular volumes of the subjects. This supports the cosmopolitan representation of patients that access care at the study centre.

The majority of the subjects $62.5 \%$ attained tertiary education in contrary to the findings by Nwajiaku and colleagues among men with infertility, where majority of the subjects only had secondary education $(68 \%)$ [21]. It is not surprising that most of the patients were civil servants with tertiary level of education as Abuja, the capital city of Nigeria is a host to a good number of senior civil servants. 
The proportion of subjects with primary infertility $(65 \%)$ and with secondary infertility $(35 \%)$ is similar to the findings obtained in South Eastern Nigeria where $65 \%$ and $35 \%$ of men had primary and secondary infertility respectively [21]. This is also similar to the findings in a recent study by Jeje and Colleagues in Lagos, Nigeria where $(62.9 \%)$ of the subjects had primary infertility [22]. This is contrary to the findings by Nwajiaku and colleagues in Southeast Nigeria,where secondary infertility (59\%) was higher than primary infertility(41\%) [21] and in a study by Owolabi in Ile-Ife Nigeria in which secondary infertility accounted for $70 \%$ [23].

A large proportion of the subjects had varicocoele (72\%) in this study which is supported by the finding that up to thirty-fifty percent of males with infertility have varicocoele [1]. However, there was no significant statistical difference between the mean testicular volume of the subjects with varicocoele and subjects without varicocoele $(p=0.0905)$.

There is an obvious difference between the right and left testicular volumes with the mean right testicular volume (RTV) and mean left testicular volume (LTV) $10.36 \pm 3.72 \mathrm{ml}$ and $9.46 \pm 3.72 \mathrm{ml}$ respectively. However, the difference is not statistically significant $(p=0.128)$. Possible explanation for this may be the high incidence of left sided varicocoeles in men with infertility [24]. This is similar to the findings by Tijani et al. Lagos, Nigeria among subfertile men [20].

The finding of an average total testicular volume of $19.83 \mathrm{ml}$ and a mean ultrasonic volume of $10.24 \mathrm{ml}$ in this study is similar to the findings of ultrasonic total testicular volume of $20.6 \mathrm{ml}$ by Lenz and co-workers in a group of infertile males [7]. However, Tijani and colleagues in Lagos, Nigeria found a mean testicular volume of $15.4 \mathrm{ml}$ in men with infertility [17]. This may be due to not excluding the pathologies that could affect testicular volume in the study. Similarly, a study by Sakamoto et al. in patients with infertility in Japan found a mean testicular volume of $13.4 \mathrm{mls}$ despite exclusion of pathologies that could affect testicular volume except varicocoeles which is similar to the MTV of $13.3 \mathrm{mls}$ found in a recent study by Manuel in Port Harcourt, Nigeria without excluding pathologies that could affect testicular volume [17]. Moreso, the testicular volumes obtained in this study were calculated manually using Lambert's formula from the ultrasound scan measured testicular length, width and height in contrast to the ultrasound machine automatically derived testicular volumes used in most studies.

There is a significant correlation between semen volume and mean testicular volume in this study $(\mathrm{r}=0.391, p<0.001)$. This is consistent with findings of similar work by Sharath among Indian men with infertility, and Hideo and Colleagues in Japan [19], [25]. This observation is expected as the testes contribute largely to semen volume [19].

The testicular volume as an indicator of fertility was found to strongly correlate with the sperm concentration using Pearson Correlation $(\mathrm{r}=0.639, p<0.001)$. This is further supported by regression analysis which showed strong impact of MTV on sperm concentration $(p<0.001)$. This finding agrees with a similar study by Tijani et al. in Lagos, Nigeria who reported an inverse relationship between mean testicular volume and severity of oligospermia among 136 men with infertility [20]. Another study in India by Sharath et al. also showed a significant correlation between testicular volume and sperm concentration $(\mathrm{r}=0.501), p<0.001)$ [19]. In a recent study by Manuel and Co-workers in Port Harcourt, among sub-fertile Nigerian men, a statistically significant positive correlation was noted between testicular volume and sperm concentration $(\mathrm{r}=0.397, p<0.001)$ [17]. Kristo and Dani in a study of men with infertility among Albanian men also noted strong significant correlation between testicular volume and sperm concentration $(\mathrm{r}=0.514, p<0.001)$.

In this study, severe oligospermia was noted at MTV of $10 \mathrm{ml}$. This finding is similar to the finding by Sakamoto et al. in Japan who found testicular volume of less than $10 \mathrm{ml}$ to be associated with severe oligospermia (sperm concentration less than 5 million sperm/ $/ \mathrm{ml}$ ) and finding by Kristo and Dani who did not find any male with normal sperm parameters with a total testicular volume under $20 \mathrm{ml}$ (with a mean of $10 \mathrm{ml}$ ) in Albania men with infertility. A study by Tijani and Colleagues in Nigeria found testicular volume of $12 \mathrm{ml}$ to be associated with severe oligospermia [20]. The higher value of MTV indicating severe oligospermia could be because pathologies that could affect testicular volume were not excluded. A recent study by Manuel in Port Harcourt Nigeria, reported severe oligospermia at MTV of $7 \mathrm{ml}$. This difference may be due to difference in sampling methods between the studies. Sakamoto et al. in Japan and Sharath et al. in India noted that total testicular volume (TTV) of $15 \mathrm{ml}$ and $16.1 \mathrm{ml}$ (MTV of $7.5 \mathrm{ml}$ and $8.05 \mathrm{ml}$ ) respectively were associated with severe oligospermia. This may be explained by effect of geographical influences on testicular volume [6], [14].

Though, the lowest testicular volumes corresponded to the lowest sperm concentration in this study as shown in figure 4 , the relationship is however not directly linear. At a mean testicular volume of $12 \mathrm{ml}$ to $14 \mathrm{ml}$, there is a slight decline in sperm concentration which is similar to the findings by Tijani et al. who noticed a change in sperm density from a testicular volume of 16 to $14 \mathrm{ml}$ [20]. This finding is not clearly understood.

The critical MTV associated with poor testicular function in this study was $10 \mathrm{ml}$ as severe oligospermia was associated with testicular volumes less than $10 \mathrm{ml}$. The question of optimum testicular volume for spermatogenesis cannot be answered as subjects with normal sperm concentration ( $>15$ millioncells $/ \mathrm{ml}$ ) were excluded in this study and no controls were used.

Though, there was a weak correlation between the mean testicular volume and percentage motility, this was not statistically significant $(\mathrm{r}=0.216, p=0.055)$. This is comparable to findings of Hideo and Colleagues in Japan who found that there is no correlation of sperm percentage motility with any measurement of the testicular size [25]. This finding is not unusual as spermatozoa mature within the epididymis and acquire the potential for capacitation and ultimately fertilization. This is contrary to the findings of similar work by Sharath Kumar et al. of significant correlation between testicular volume and sperm motility among subfertile Indian men [19]. Also, a study by Kristo among Albanian subfertile men found a positive correlation between mean testicular volume and sperm motility $(\mathrm{r}=0.484, p<0.001)$.

There was a weak correlation between the percentage normal sperm forms and mean testicular volume but not statistically significant $(\mathrm{r}=0.076, p=0.502)$. This is comparable to the findings by Kristo and Dani among Albania sub-fertile men who found positive correlation 
between mean testicular volume and percentage normal forms that was statistically significant.

\section{LIMITATION}

This study did not use normal fertile men as controls due to religious and cultural beliefs in our environment. Therefore, the optimum testicular volume (OTV) indicating nearly normal function could not be ascertained.

\section{CONCLUSION AND RECOMMENDATION}

The mean ultrasonic testicular volume in men with infertility in this study was $10.24 \mathrm{ml}$ and there was a positive correlation of MTV with semen volume and sperm concentration. Although, there was correlation of MTV with sperm motility and morphology, this was not significant. The critical mean ultrasonic testicular volume indicating poor function (severe oligospermia) was found to be $10 \mathrm{ml}$. This study has shown that the mean ultrasonic testicular volume can be a pointer to semen volume and sperm concentration in evaluating men with infertility. We therefore recommend from our study, the use of ultrasonic mean testicular volume as a useful tool in prognosticating semen volume and sperm concentration in the evaluation of male infertility. However, a study with controls is needed to determine the optimum testicular volume for the general population.

\section{REFERENCES}

[1] JW Thomas and FS James. Male infertility. In: Smith's General Urology,18th ed. EA Tanagho and JW McAninch (Eds). McGraw Hill Lange, 2013. p. 687-717.

[2] JR Patrick JR, HC Frank HC. WHO Manual for the standardized investigation and Diagnosis of the infertile male. Cambridge University Press,28 Mar 2000.

[3] RS Sharma, KK Gaur, PC Pal, M Manocha, D Tomar, AA Khan et al. Semen characteristics: Advancement in andrological assessment. Indian J Clin Biochem. 2005;20(1):173.

[4] AC Umezulike, ER Efetie. Psychological trauma of infertility in Nigeria. Int J Obs Gynaecol. 2004;84:178-180.

[5] A Idrisa, E Oyiyi, O Tomfafi, TB Kumara, HU Pindiga. Male contribution to Infertility in Maiduguri, Nigeria. Trop J Obstet Gynaecol.2000;18(2):87-89.

[6] S Niederberger. Male Infertility. In: Campbell-Walsh Urology,10th ed. Wein Kavousi, Novick Partin: Elsevier Sanders, 2012.p.17811819.

[7] S Lenz, A Giwercman, A Elsborg, KH Cohr, JE Jelnes, E Carlsen, et al. Ultrasonic testicular texture and size in 444 men from the general population: correlation to semen quality. Eur Urol. 1993;24(2):231238 .

[8] H Takihara, MJ Cosentino, J Sakatoku, AT Cockett. Significance of testicular size measurement in andrology: II. Correlation of testicular size with testicular function. $J$ Urol. 1987;137(3):416-419.

[9] ED Kim, LI Lipshultz. Role of ultrasound in the assessment of male infertility. J Clin Ultrasound. 1996;24(8):437-453.

[10] S Lenz, JK Thomsen, A Giwercman, NT Hertel, J Hertz, NE Skakkebaek. Ultrasonic texture and volume of testicles in infertile men. Hum Reprod. 1994;9(5):878-881.

[11] A Aribarg, W Kenkeerati, V Vorapaiboonsak, S Leepipatpaiboon, TM Farley. Testicular volume, semen profile and serum hormone levels in fertile Thai males. Int J Androl 1986;9(3):170-180.

[12] L Bujan, R Mieusset, A Mansat, JP Moatti, C Mondinat, F Pontonnier. Testicular size in infertile men: relationship to semen characteristics and hormonal blood levels. Br J Urol.1989;64(6):632637.

[13] TU Mbaeri, JC Orakwe, AME Nwofor, CK Oranusi, OO Mbonu. Ultrasound measurements of testicular volume: Comparing the three common formulas with the true testicular volume determined by water displacement. African J Urol. 2013;19(2):69-73.

[14] H Takihara, J Sakatoku, M Fujii, T Nasu, MJ Cosentino, AT Cockett. Significance of testicular size measurement in andrology. I. A new orchiometer and its clinical application. Fertil Steril. 1983;39(6):836840.

[15] HJ Paltiel, DA Diamond, J DiCanzio, D Zurakowski, JG Borer, A Atala. Testicular volume: comparison of orchidometer and US measurements in dogs. Radiology.2002;222(1):114-119.

[16] H Sakamoto, K Saito, M Oohta, K Inoue, Y Ogawa, H Yoshida. Testicular Volume Measurement: Comparison of Ultrasonography, Orchidometry, and Water Displacement. Urology. 2007;69(1):152157.

[17] BA Manuel, EW Ugboma, NC Nwankwo. Relationship between Testicular Volume and Sperm Count in Infertile Men in Southern Nigeria.AJMAH.2017;4(1):1-6.

[18] A Kristo, E Dani. The correlation between ultrasound testicular volume and conventional semen parameters in Albanian subfertile males. Maced J Med Sci. 2014;7(3):464-466.

[19] C Sharath Kumar, M Najafi. Assessment of Testicular Volume in Correlation with Spermiogram of Infertile Males in South India. Adv Stud Biol. 2013; 5(7):327-335.

[20] KH Tijani, BO Oyende, GO Awosanya, RW Ojewola, AO Yusuf. Assessment of testicular volume: A comparison of fertile and subfertile West African men. African J Urol. 2014;20(3):136-140.

[21] LA Nwajiaku, II Mbachu, L Ikeako. Prevalence, clinical pattern and Major Causes of Male infertility in Nnewi, South East Nigeria: A five year review. Afrimedic J.2012; 3(2).

[22] EA Jeje, TO Alabi, RW Ojewola, SO Ogunjimi. Male infertility: An audit of 70 cases in a single centre. African J Urol. 2016;22:223-226.

[23] A Owolabi, OB Fasuba, SO Ogunniyi. Semen quality of male partners of infertile couples in Ile-Ife, Nigeria. Niger $J$ Clin Pract. 2013;16(1):37-40.

[24] D Cornu, K Amar, N Hamda, N Thiounn, O Helenon, JF Moreau. Imaging in male hypofertility and impotence. BJU Int. 2000;86(1):153-163.

[25] H Sakamoto, K Saito, Y Ogawa, H Yoshida. Testicular Volume Measurements Using Prader Orchidometer Versus Ultrasonography in Patients with Infertility. Urology. 2007;69(1):158-162. 